\title{
A Novel Planar Monopole Antenna with Truncated Ground Plane for Wireless Communication
}

\author{
R Vadivelu, G Santhakumar
}

\begin{abstract}
In this paper, triple-band planar monopole Microstrip Antenna intended for different applications like Bluetooth, Wi-Fi, Wireless LAN (2.4 GHz), LTE 2500 band, WiMax $(3.5 \mathrm{GHz})$, and a piece of C-band applications. The reception apparatus has been intended to work at different recurrence groups, for example, 2.25 - $2.5 \mathrm{GHz}, 3.32-3.97 \mathrm{GHz}$, and $5.90-8.67 \mathrm{GHz}$ individually. The proposed receiving antenna comprises of a planar monopole reception apparatus imprinted on RT/duroid 5880 substrate (through a general permittivity of 2.2 and loss tangent of 0.0009) and the base side printed with a truncated ground. The planar monopole reception apparatus has been viably structured and reproduced by utilizing Ansys-HFSS design tool. The component of the proposed receiving antenna is $40 \times 28.4 \times 1.575 \mathrm{~mm}^{3}$. The reenacted outcome shows return loss, voltage standing wave ratio (VSWR), radiation pattern, and gain of the Antenna. Also, the truncated ground plane structure is straightforward, vigorous and possesses little space, building it appropriate for different applications.
\end{abstract}

Index Terms: Microstrip monopole antenna, impedance transfer speed, return misfortune, VSWR and radiation design.

\section{INTRODUCTION}

In the ebb and flow remote correspondence framework, innovative work endeavors have gone for improving reception apparatus execution with the little size. Microstrip strip antenna assumes a crucial job in the remote correspondence. Microstrip receiving wires have a higher, approaching potential towards Circularly Polarized (CP) reception apparatuses that has various alluring highlights like the position of safety, weightless, comparability to an assortment of mounting structures and similarity with the printed circuit innovation. The CP microstrip reception apparatus can get directly captivated waves that have an enemy of blurring highlight to improve the remote correspondence framework limit [1]. CP reception apparatuses can diminish the polarization crisscross between the transmitting and accepting, receiving wires of the

Revised Manuscript Received on December 30, 2019.

* Correspondence Author

R Vadivelu, Department of ECE, Sri Krishna college of Technology, Coimbatore, India. Email: vadiveluece@gmail.com

G Santhakumar Department of ECE, Sri Krishna college of Technology, Coimbatore, India..

(C) The Authors. Published by Blue Eyes Intelligence Engineering and Sciences Publication (BEIESP). This is an open access article under the CC BY-NC-ND license (http://creativecommons.org/licenses/by-nc-nd/4.0/) framework and the multipath impedance likewise has been decreased. It is smarter to pick CP receiving wires for Wireless LAN/Wi-Fi applications as opposed to straightly spellbound (LP) reception apparatuses[2]. In the Current situation, a data transfer capacity improvement is likewise

ending up increasingly, however, it is hard to grow the limit of remote correspondence frameworks. CP multiband planar radio antennas are relied upon to be the promising space that underpins different remote correspondence applications. The CP Microstrip antenna encouraging has classified as single-bolstered or double sustained. The single-feed receiving antenna does not require any outside polarizer. The connection between the ideal feed area and recurrence of the $\mathrm{CP}$ wave has tested, and results have been discussed in [3]. Planar monopole reception antennas for multi-band radio terminals are planned with strong metal transmitting components to uncover wide data transmission [4]. The single-feed configuration gives better arrangements yet and displays a constrained Axial Ratio (AR) data transfer capacity [5]. CP radio wires are planned with a Microstrip feed line to an annular-ring opening receiving wire at two reasonably chosen positions to coordinate the impedance [6]. Single layer, double band CP Microstrip receiving antenna with a restricted AR transmission capacity has been exhibited. The diminished edge reception antenna uncovers the best pivotal proportion, and yet, it has decreased AR data transfer capacity further $[7,8]$. Independently encouraged wide band circularly enraptured opening reception antenna have detailed that the addition is just $3.5 \mathrm{~dB}$. In addition, the fixed radio antennas with printed opening are utilized in applications that require more data transfer capacity [9]. The disadvantages of $\mathrm{CP}$ antennas are its massive size and tight data transmission. In this paper, the proposed receiving antenna of planar monopole with the truncated ground plane for wireless application has been examined, and the outcomes have been exhibited in the accompanying segments [10]. The proposed reception apparatus fulfills the accompanying operational groups: $2.4 \mathrm{GHz}$ Bluetooth $(2.402-2.480 \mathrm{GHz}$ determined by the IEEE 802.11 standard), $2.4 \mathrm{GHz}$ Wi-Fi/WLAN (2.4-2.484 GHz characterized by IEEE 802.11b/g guidelines), LTE 2500 band, 3.5 WiMAX (3.4-3.69 GHz indicated by IEEE 802.11a models) and a piece of $\mathrm{C}$ band. 


\section{A Novel Planar Monopole Antenna with Truncated Ground Plane for Wireless Communication}

Copper strips accomplish Triple-band activity of the proposed radio antenna.

\section{ANTENNA DESIGN}

The geometry of the proposed planar monopole antenna is as appeared in Fig.1. The radiator is imprinted on the top surface of the RT/duroid 5880 substrate with the thickness of $1.575 \mathrm{~mm}$, and the base surface printed with the truncated ground plane. The fundamental motivations to pick this substrate material are isotropic, uniform electrical properties over recurrence, uniform electrical property over frequency, and low dampness assimilation. The dielectric consistent $\left(\epsilon_{\mathrm{r}}\right)$ and scattering factor $(\tan \delta)$ of the substrate are 2.2 and 0.0009 . The thickness of the copper track on both the surface is $0.035 \mathrm{~mm}$. The component of the substrate $(\mathrm{L} \times \mathrm{W})$ is $40 \times 28.4 \mathrm{~mm}^{2}$. Table I demonstrates the geometrical parameters of the proposed antenna. High-Frequency Structure Simulator (HFSS) is utilized to plan the proposed receiving antenna. The planar monopole antenna is sustained by means of a $50 \mathrm{ohm}$ quarter-wave line Microstrip feed with width $\mathrm{W}_{\mathrm{f}}=4.8 \mathrm{~mm}$ is determined by utilizing equation (1). The width of the feed is utilized to accomplish the impedance coordinating over the whole frequency extend. The left-side top edge strip creates reverberation at the lower band, while the right-side pieces of the Microstrip feed produce reverberation in the upper-band. It is a record of the width of the strips. The truncated ground is utilized to lessen the proliferation of surface waves delivered by the Microstrip transmission line.

$\left.\begin{array}{l}Z_{o}=\frac{120 \pi}{\sqrt{\varepsilon_{\text {eff }}}} \times \frac{1}{\left(\frac{w}{h}+1.393+0.677 \times \ln \left(\frac{w}{h}+1.444\right)\right)} \\ \varepsilon_{\text {eff }}=\frac{\varepsilon_{r}+1.0}{2}+\frac{\varepsilon_{r}-1.0}{2}\left[\frac{1}{\sqrt{1+\frac{12 h}{w}}}\right]\end{array}\right\}$

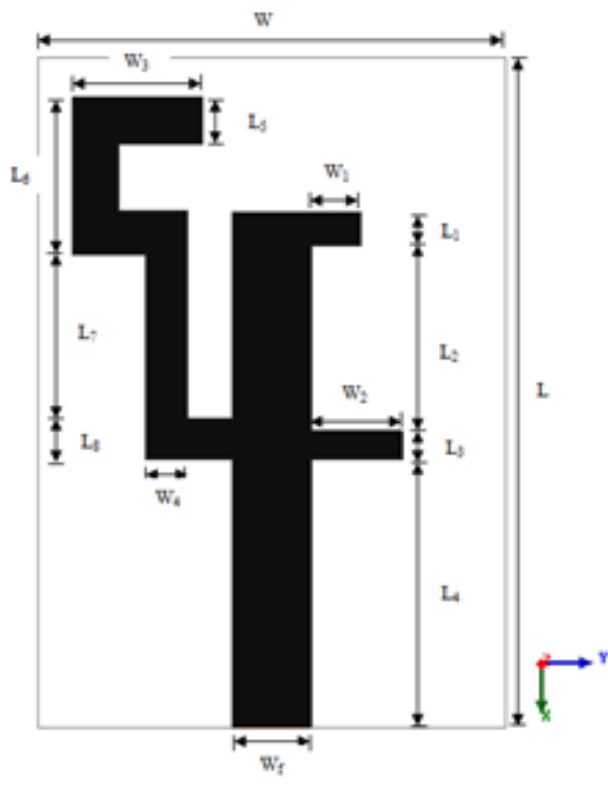

(a)

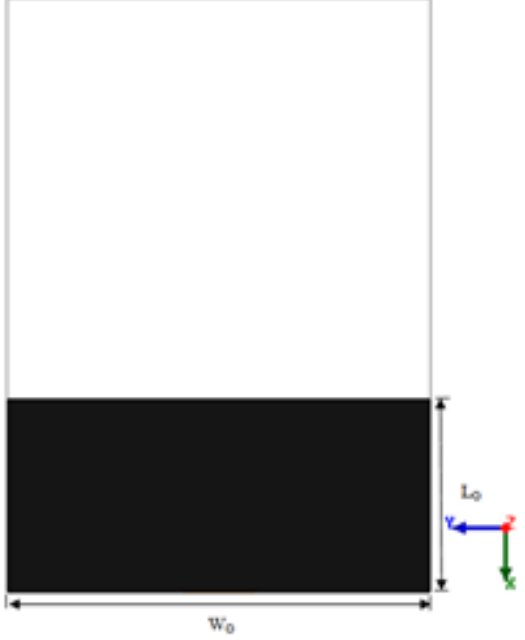

(b)

Fig. 1.Proposed truncated reception apparatus geometry (a) Top View, (b) Bottom View

TABLE I. Geometrical Parameters Of The Antenna

\begin{tabular}{|c|c|}
\hline Parameter & Value (mm) \\
\hline $\mathrm{L}$ & 28.4 \\
\hline $\mathrm{W}$ & 2 \\
\hline $\mathrm{L}_{1}$ & 11.102 \\
\hline $\mathrm{L}_{2}$ & 1.698 \\
\hline $\mathrm{L}_{3}$ & 16 \\
\hline $\mathrm{L}_{4}$ & 2.845 \\
\hline $\mathrm{L}_{5}$ & 9.5 \\
\hline $\mathrm{L}_{6}$ & 9.6 \\
\hline $\mathrm{L}_{7}$ & 2.602 \\
\hline $\mathrm{L}_{8}$ & 3 \\
\hline $\mathrm{W}_{1}$ & 5.5 \\
\hline $\mathrm{W}_{2}$ & 7.9 \\
\hline $\mathrm{W}_{3}$ & 2.447 \\
\hline $\mathrm{W}_{4}$ & 4.8 \\
\hline $\mathrm{W}_{\mathrm{f}}$ & 13 \\
\hline $\mathrm{L}_{\mathrm{G}}$ & 28.4 \\
\hline $\mathrm{W}_{\mathrm{G}}$ & \\
\hline & \\
\hline
\end{tabular}

III. RESULTS AND DISCUSSION

\section{A. Return Loss and VSWR}

The reproduced return loss of the proposed reception apparatus is appeared as shown in the Fig. 2. It is found from the Fig. 2, that the receiving antenna resonates in the triple band, for example, $2.25-2.50 \mathrm{GHz}, 3.32-3.97 \mathrm{GHz}$, and $5.90 \mathrm{GHz}-8.67 \mathrm{GHz}$. The $10-\mathrm{dB}$ impedance data transfer capacity and a partial transmission capacity of the Microstrip antenna are given by

$$
\begin{aligned}
& \text { Bandwidth }=\frac{f_{H}-f_{L}}{f_{c}} \\
& \text { \%Bandwidth }=\frac{f_{H}-f_{L}}{f_{L}} \times 100
\end{aligned}
$$


Utilizing equation (2), the data transfer capacity of the lower band is $0.105 \mathrm{GHz}$, while the transmission capacity of the center band and the upper band are $0.178 \mathrm{GHz}, 0.380$ $\mathrm{GHz}$. These bands are covering the Bluetooth, Wi-Fi, Wireless LAN (2.4 GHz), LTE 2500 band, WiMax, and a piece of the C-band Systems. The Fractional data transmission of the comparison groups is $10.5 \%, 17.8 \%$, and $38 \%$ by utilizing equation (3). The Voltage Standing Wave Ratio (VSWR) plot of the proposed truncated antenna is appeared as in the Fig.3. VSWR equivalents of two gives a return loss of roughly equivalents to - $10 \mathrm{~dB}$ and it is set as far as possible for a coordinated receiving antenna. The Quality (Q) Factor is a proportion of recurrence selectivity. Q factor of the antenna is determined as $\mathrm{Q}=\left(\mathrm{f}_{0} /\right.$ Bandwidth $)$.

\section{B. Radiation Patterns}

Fig.4 demonstrates the recreated radiation pattern of the proposed recieving antenna at $2.4 \mathrm{GHz}, 3.5 \mathrm{GHz}$, and 6.26 $\mathrm{GHz}$ in the E-plane (xz-plane) and H-plane (yz-plane) individually. From the figure, the proposed antenna displays the bi-directional pattern in the E-plane and omnidirectional patten in the H-plane over the whole recurrence groups.

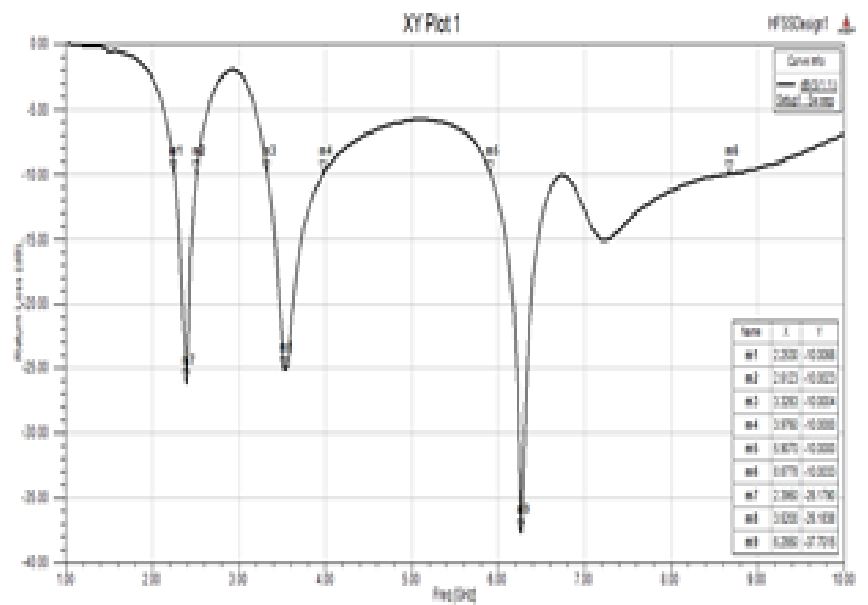

Fig. 2. Simulated return loss of the proposed antenna.

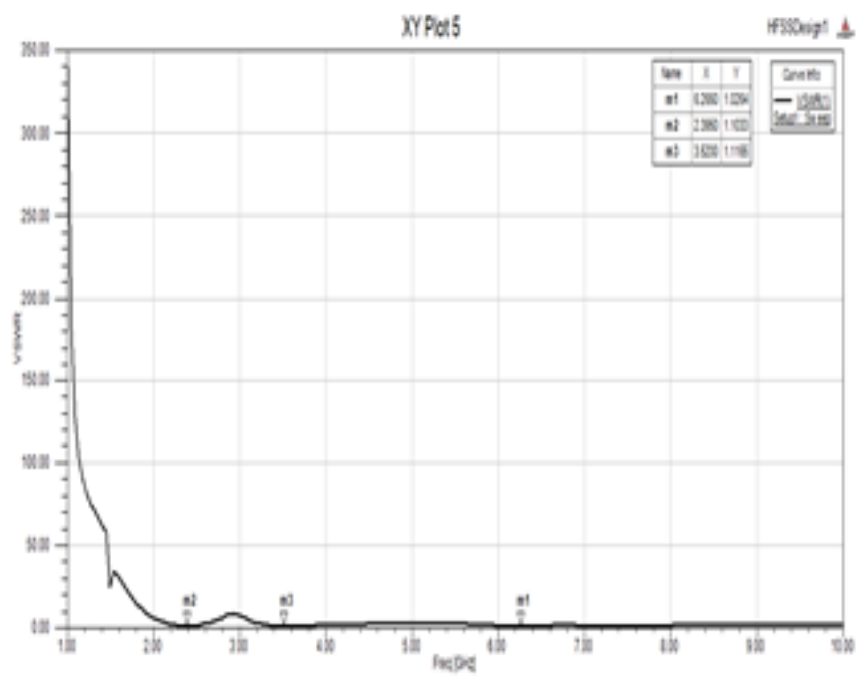

Fig. 3. Simulated VSWR of the proposed antenna

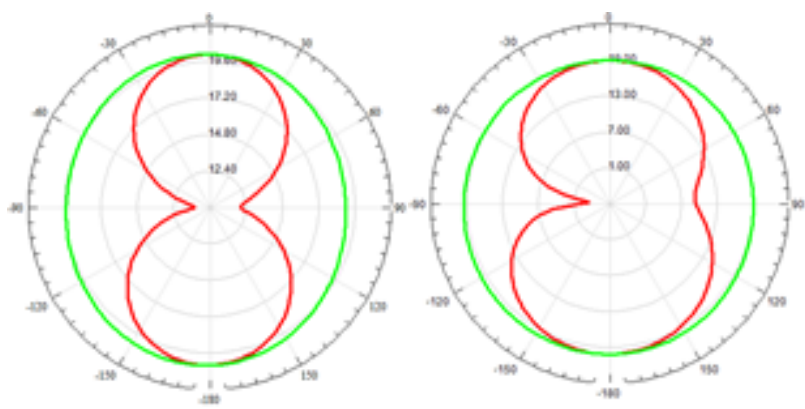

(a)

(b)

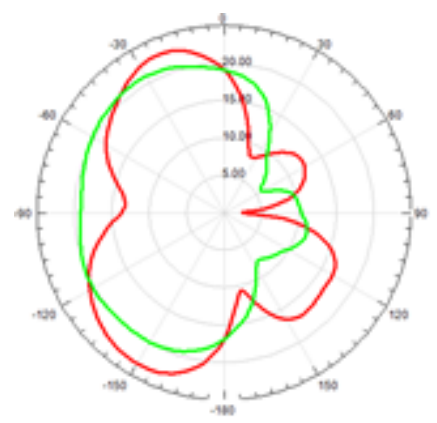

(c)

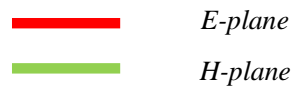

Fig. 4. Simulated E-plane and $H$-plane radiation pattern of the proposed antenna at (a) $2.4 \mathrm{GHz}$, (b) $3.5 \mathrm{GHz}$, and (c) $6.26 \mathrm{GHz}$.

\section{Gain and Efficiency}

Fig.5 demonstrates the simulated peak gain of the proposed antenna over the ideal band of frequencies. The peak gains are $7.63 \mathrm{~dB}$ to $9.80 \mathrm{~dB}$, and $4.51 \mathrm{~dB}$ to $3.57 \mathrm{~dB}$ for the lower band and center band frequencies of $2.25-2.50$ $\mathrm{GHz}$, and 3.32 - $3.97 \mathrm{GHz}$ separately. The different parameters of the proposed antenna are condensed in Table 2.

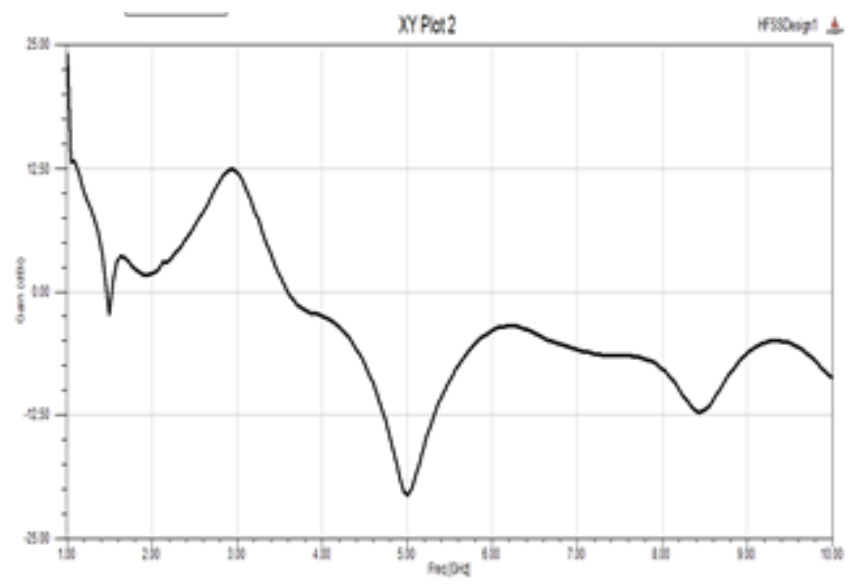

Fig. 5. The Simulated gain of the proposed antenna

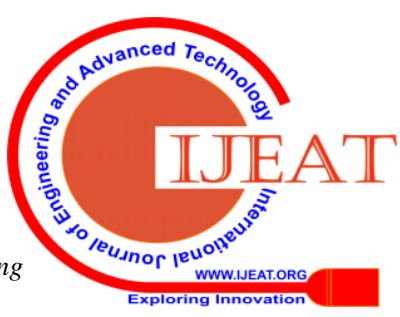


A Novel Planar Monopole Antenna with Truncated Ground Plane for Wireless Communication

TABLE II. Summarization Of Various Parameters Of The Proposed Antenna

\begin{tabular}{|c|c|c|c|}
\hline \multirow{2}{*}{$\begin{array}{c}\text { Frequency } \\
\text { Band / } \\
\text { Parameters }\end{array}$} & $\begin{array}{c}2.25-2.5 \\
\mathrm{GHz}\end{array}$ & $\begin{array}{c}3.32-3.97 \\
\mathrm{GHz}\end{array}$ & $\begin{array}{c}5.90-8.67 \\
\text { GHz }\end{array}$ \\
\hline & Lower Band & Middle Band & Upper Band \\
\hline $\begin{array}{l}\text { Resonant } \\
\text { Frequency }\end{array}$ & $2.4 \mathrm{GHz}$ & $3.5 \mathrm{GHz}$ & $6.26 \mathrm{GHz}$ \\
\hline Bandwidth & $0.105 \mathrm{GHz}$ & $0.178 \mathrm{GHz}$ & $0.380 \mathrm{GHz}$ \\
\hline $\begin{array}{l}\text { Fractional } \\
\text { Bandwidth }\end{array}$ & $10.5 \%$ & $17.8 \%$ & $38 \%$ \\
\hline $\begin{array}{l}\text { Quality } \\
\text { Factor (Q) }\end{array}$ & 9.5 & 5.6 & 2.62 \\
\hline Peak Gain & $\begin{array}{c}7.63 \mathrm{dBi} \text { to } \\
9.80 \mathrm{dBi}\end{array}$ & $\begin{array}{c}4.51 \mathrm{dBi} \text { to } 3.57 \\
\mathrm{dBi}\end{array}$ & $\begin{array}{c}3.95 \mathrm{dBi} \text { to } 3.81 \\
\mathrm{dBi}\end{array}$ \\
\hline
\end{tabular}

\section{CONCLUSION}

An epic planar monopole antenna with the truncated ground for triple-band activity is displayed. The proposed antenna comprises of different widths of strips that empower various resonant groups. Recreated results demonstrate that the ideal working bandwidth, radiation pattern, and peak gain for Bluetooth, Wi-fi (2.4 GHz), WLAN (2.4 GHz), LTE 2500 band, and WiMax (3.5 GHz) applications that can be accomplished. The proposed antenna can be the best suited for different wireless applications because of its basic structure, great radiation pattern and peak gain that increase over the frequencies.

\section{REFERENCES}

1. Oteng Gyasi Kwame1, Yongjun Huang,Guangjun Wen, Affum Emmanuel Ampoma and Wei Hu, "Tri-band Planar Monopole Antenna With Dual Band Circular Polarization”, IEEE Transactions on Antennas and Propagation, Vol. 31, 2533 - 2534, 2017.

2. Udaiyakumar R, Janani T, Vigneshram R, Maheswar R, Iraj S Amiri, "A Fan-Beam Stacked Array X-Band Radar Antenna", National Academy Science Letters-India, https://doi.org/10.1007/s40009-019-00824-y

3. Md. Nabil Srifi, V K Palukuru, Mohamed Essaaidi, and Heli Jantunen, "Compact planar monopole Antenna for 3G and UWB Applications", Microw. and Opt. Technol. Lett., Vol. 51, No. 8, pp. 1939-1942, Aug. 2009.

4. M. Ammann, "A wideband monopole for reconfigurable multiband radio terminals," in Proc. IEEE Int. Symp. Antennas and Propagation, vol. 1, Boston, MA, July 2001, pp. 170-173.

5. Sharma, P. and K. Gupta, "Analysis and optimized design of single feed circularly polarized microstrip antennas", IEEE Transactions on Antennas and Propagation, Vol. 31, 949-955, Nov. 1983.

6. T. V. Hoang and H. C. Park, "Very simple $2.45 / 3.5 / 5.8 \mathrm{GHz}$ triple band circularly polarised printed monopole antenna with bandwidth enhancement", Electron. Lett., vol. 50, no. 24, pp. 1792-1793, 2014.

7. Wu, T., Shi, X.W., Li, P., and Bai, H. "Tri-band microstrip-fed monopole antenna with dual-polarisation characteristics for WLAN and WiMAX applications”, Electron. Lett., 49, (25), pp. 1597-1598, 2013.

8. M. T. Tan and B. Z. Wang, "A Dual-Band Circularly Polarized Planar Monopole Antenna for WLAN/Wi-Fi Applications", in IEEE Antennas and Wireless Propagation Letters, vol. 15, pp. 670- 673, 2016.

9. Sumathi.K, Malathy.S, Jaipriya.S, Priyanka B, "Design and Analysis of Omega Shaped Slotted Multiband Antenna”, International Journal of Engineering and Advanced Technology (IJEAT), vol. 8, no.5, pp 193-197. Jun 2019.

10. R. Udaiyakumar, R. Maheswar, T. Janani, R. Vigneshram, Iraj S Amiri, P Yupapin, "Performance Enhancement of Shorted Polygonal Archimedean Spiral Antenna Using Hybrid Reflector", AEU International Journal of Electronics and Communications, vol. 107, pp. 1-8. Jul 2019.

\section{AUTHOR'S PROFILE}

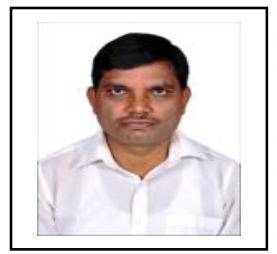

R Vadivelu is presently working in the ECE Department as Associate Professor at Sri Krishna College of Technology, Coimbatore, India. Obtained his B. Sc., in Physics from Bharathiar University, M. Sc., in Electronics from Madras University, M. Tech., Electronics, Cochin University of Science and Technology and Ph. D in ICE from Anna University, India in1995,1998,2001 and 2015. He authored various Research Articles in Cognitive Radio, Spectrum sensing domain. Areas of interest of the author include mm Wave Antennas, 5G antennas, Spectrum Sensing, RADAR Systems and Microwave Communication.

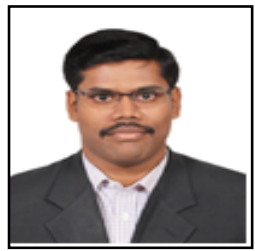

G Santhakumar received his Undergraduate degree in Electronics and Communication engineering from the Anna University in 2010 and received his postgraduate degree in Communication system in 2012 from Anna University. Presently the author working in the ECE Department as Assistant Professor in Sri Krishna College of Technology, Coimbatore, India. His main research interests include $\mathrm{mm}$ Wave antennas, 5G antennas and Communication. 